\title{
Placental Plasmodium Parasitemia and Pregnancy Outcome In Asymptomatic Parturients at Term In A Tertiary Institution South East Nigeria
}

\section{Wilson Ndukwe Nwigboji}

Alex EKwueme Federal University Teaching Hospital Abakaliki

John Okafor Egede ( $\nabla$ egedejohno@yahoo.com )

Alex Ekwueme Federal University Teaching Hospital, Abakaliki, Ebonyi State, Nigeria https://orcid.org/0000-0002-5470-755X

\section{Peace Chinyere Igwe}

Alex Ekwueme Federal University Teaching Hospital Abakaliki

\section{Matthew Nwali Igwe}

Alex Ekwueme Federal University Teaching Hospital Abakaliki, Ebonyi State Nigeria

\section{Gregory Chinedu Nwigwe}

Alex Ekwueme Federal University Teaching Hospital, Abakaliki, Nigeria

Alfred Nnabugwu Adiele

Alex Ekwueme Federal University Teaching Hospital Abakaliki, Ebonyi State

\section{Felix 0 Edegbe}

AEFUTHA: Alex Ekwueme Federal University Teaching Hospital Abakaliki

Ikechukwu Bonaventure Okechukwu Dimejesi

Alex Ekwueme Federal University Teaching Hospital Abakaliki

\section{Lawrence 0 Omo-Aghoja}

DElta State University Abraka

\section{Research}

Keywords: malaria in pregnancy, placental malaria, low birth weight, congenital malaria

Posted Date: September 15th, 2021

DOI: https://doi.org/10.21203/rs.3.rs-864681/v1

License: (c) (1) This work is licensed under a Creative Commons Attribution 4.0 International License.

Read Full License 


\section{Abstract}

Background: Malaria in pregnancy is a major public health problem in sub-Saharan Africa and can result in placental malaria with its associated adverse pregnancy outcomes.

Method: This was a case control study involving 190 consenting, asymptomatic, booked parturients, recruited consecutively at 36 week. The aim was to determine the effect of placental malaria on pregnancy outcome in asymptomatic women delivering at term. The participants were screened for malaria parasites using peripheral blood film. Based on their results, the participants were grouped into parasitemia positive cases (Group 1) and parasitemia negative controls (Group 2). Both groups were then followed up in the clinic till they presented in labour at term. In labour, participants' peripheral venous blood sample were collected and used to determine intrapartum haematocrit and peripheral parasitemia. After delivery, cord blood and a section of the placenta were collected for investigation.

Data analysis: Collected data were analysed using Statistical Product and service solutions (SPSS) software (version 20). Numerical variables were presented as mean and standard deviation (Mean SD), while categorical variables were presented as numbers and percentages. Chi-square test $\left(X^{2}\right)$ was used to compare qualitative variables. Odds ratio $(\mathrm{OR})$ and Confidence interval $(\mathrm{Cl})$ were used to observe the odds of outcomes. A p-value 0.05 was considered statistically significant.

Results: The prevalence of placental malaria and congenital malaria were $41.05 \%$ and $29.47 \%$ respectively. Birth weight, APGAR score, NICU admission or congenital malaria were not statistically significant between the two groups. The mean birth weight was $3.16 \pm 0.5 \mathrm{~kg}$ while $17.89 \%$ had low birth weight. There was also no significant difference between the two groups in terms of the association of placental parasitaemia and maternal anaemia or dose of IPT taken. There was no significant association between placental parasitaemia and low parity. Multivariate logistic regression analysis of maternal anaemia and low birth weight showed significant placental parasitaemia in both cases $(p=0.004)$.

Conclusion: Placental parasitaemia is a major complication of malaria in pregnancy and is associated with adverse feto-maternal effects. Early booking and uptake of intermittent preventive therapy with sulphadoxine-pyrimethamine may help reduce the adverse effects.

\section{Introduction}

Despite the integrated efforts to control malaria in endemic areas, placental malaria remains a significant cause of maternal and perinatal morbidity and mortality ${ }^{1,2,3}$. Malaria in pregnancy remains a major public health problem especially in sub-Saharan Africa, where approximately 25 million pregnant women are at risk of Plasmodium falciparum infestation per year. About $25 \%$ of these pregnant women have evidence of placental parasitemia during delivery, even without symptoms of malaria, with associated increased risk of maternal and perinatal morbidity and mortality ${ }^{1}$. 
Pregnant women are known generally to demonstrate an increased susceptibility to malaria ${ }^{4}$. Although the mechanism for this is poorly understood, pregnant women have reduced immune response and therefore less effectively clear malaria parasites ${ }^{5}$. Malaria during pregnancy, especially in endemic areas, is characterised by sequestration of infected erythrocytes in placental intervillous spaces, binding chondroitin sulphate A (CSA) and resulting in placental malaria. Placental malaria leads to adverse pregnancy outcomes such as miscarriages, preterm births, low birth weight, stillbirth and maternal anaemia ${ }^{5,6,7}$. Available evidence indicate that primigravidae and secondigravidae (to a lesser extent) are more affected than multigravidae because of development of immunity to the parasites in subsequent pregnancies by the latter ${ }^{1,4,8}$.

Malaria is caused mainly by four species of plasmodium namely Plasmodium falciparum, P. vivax, P. malariae, and P. ovale. It is usually spread through the bite of an infected female anopheles mosquito but may also follow transfusion of infected blood or use of syringe contaminated with infected blood ${ }^{4,9}$. During a blood meal, the female anopheline mosquito inoculates plasmodial sporozoites from its salivary gland. These sporozoites are motile and circulate in the blood stream for about 30 minutes before taking refuge in the hepatocytes where they multiply, producing thousands of merozoites. The swollen hepatocytes eventually rupture, releasing merozoites into the blood stream and starting the symptomatic blood stage of the infection. Synchronous rupture of ring forms every 48 hours as in P. falciparum or every 72 hours in the case of P. malariae corresponds to febrile paroxysms ${ }^{4,10}$.

Placental malaria is defined as the accumulation of plasmodium-infested erythrocytes in the intervillous spaces in the placenta, causing histological changes including leukocyte-induced damage to the trophoblastic basement membrane ${ }^{11,12}$. This leads to pathological alterations like preterm delivery, intrauterine growth restriction, fetal anaemia, low birth weight, maternal anaemia, congenital malaria and perinatal mortality ${ }^{13,14}$. The placenta is a highly vascularised organ and a privileged site for parasite sequestration and development ${ }^{15,16}$. Placental malaria is a feature that is exclusively related to $P$. falciparum ${ }^{17}$.This is because of the presence of Plasmodium falciparum erythrocyte membrane protein 1 (PfEMP1), a multimeric protein encoded by a family of roughly 60 variant (var) genes ${ }^{18-20}$. The PfEMP1 is the main adhesion receptor which adheres the parasite-infested erythrocytes to the chondroitin sulphate $A(C S A)$ expressed in the placenta ${ }^{20-22}$. This binding of infested erythrocytes to CSA is mediated by VAR2CSA antigen, a variant of the PfEMP1 family proteins ${ }^{23-25}$. The multiplicity of VAR2CSA-type genes confers to $P$. falciparum parasites a greater capacity for antigenic variation and evasion of immune response $e^{26,27}$. This placenta sequestration of parasites, is believed to occur mainly to avoid splenic removal of infected erythrocytes ${ }^{12,17,28}$. Sequestration causes micro-circulatory obstruction, impaired tissue perfusion, and inflammatory cells activation, and is linked to the severity of the disease ${ }^{14,29}$. Acquisition of antibodies against VAR2CSA occurs during pregnancy after exposure to infected erythrocytes sequestering in the placenta. The concentrations of these antibodies and also antibodies that inhibit binding of infected erythrocytes to CSA increase with parity $20,30,31$. Thus in 
Unbooked status, erratic antenatal visits, and poor antenatal coverage of intermittent preventive therapy for malaria (IPT), especially in sub-Saharan Africa have resulted in increased risk of contracting malaria during pregnancy with associated increased maternal and perinatal morbidity and mortality ${ }^{2}$. It's been shown that in endemic area, the sequestration of plasmodium parasites in the placenta makes them unavailable in the peripheral blood thereby causing no symptoms to the affected women ${ }^{16,34}$. Such asymptomatic patients would therefore see no need for malarial diagnosis and treatment, leading to the aforementioned complications even in the face of potent anti-malarial agents and preventive measures that would have circumvented them ${ }^{11,35,36}$. Since placental tissue can only be studied at delivery, providing a single snapshot of a dynamic process of infection and response ${ }^{37}$, findings from this study will help inform public health managers and policy makers on the situation of malaria risk factors and the impact of IPT strategy for malaria control in pregnancy in Sub Saharan African region.

Despite the adverse effects of placental malaria on pregnancy outcome, especially in endemic region like sub-Saharan Africa, detailed data on the pattern of placental malaria and its feto-maternal effects are scarce. The few available data show conflicting results ${ }^{3,8}$ with no clearly defined pattern of pregnancy outcome. Majority of these studies were carried out in middle and low-income countries. The aim of this study is therefore to determine the association between placental parasitemia and pregnancy outcome in asymptomatic women in labour. It is hoped that study may help update public health managers and policy makers on risk factors of placental malaria and may help to access the impact of intermittent preventive therapy using Sulphadoxine-Pyrimethamine (IPT-SP) strategy for malaria prevention in this region of the country.

\section{Materials And Method}

This was a case control study comparing different fetal outcomes and maternal characteristics of parturients with positive parasitemia (cases) and those that have negative parasitemia (controls).

Study population were booked parturients at 36 weeks gestation who had their antenatal care at the Alex Ekwueme Federal University Teaching Hospital, Abakaliki (AEFUTHA). The institution is a tertiary hospital in Ebonyi state and has delivery rate of about 3000 per annum. The study was carried out over a six months period between 1 June, 2018 and 30 November, 2018. As part of antenatal care education, booked women are counselled on the need to take their routine drugs and to prevent malaria using IPT and LLITNs. Women who have symptoms of malaria are actively treated as per departmental protocol.

Parturients who met the inclusion criteria (booked parturients with singleton pregnancy at 36 weeks gestation, asymptomatic of malaria infestation, and willing to participate in the study) were recruited by consecutive sampling technique. They were followed up till they presented in labour. A parturient was booked if she attended antenatal care in the study centre and had been reviewed with her routine antenatal investigations and also received at least one dose of IPT. Booked parturients receive IPT as a major component of their antenatal care. Exclusion criteria include unbooked women, women with 
pregnancy complications like diabetes mellitus, hypertensive disorders of pregnancy, antepartum haemorrhage, and parturients who declined consent to the study.

The minimum sample size was determined using the formula for calculating sample size for case control studies 53

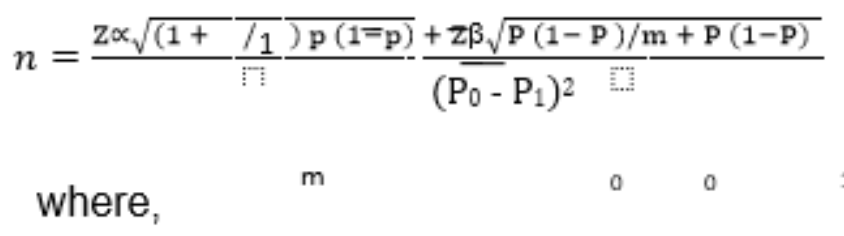

$\mathrm{n}=$ minimum sample size

$Z_{a}=$ standard normal variate corresponding to 1.96 (at $5 \%$ type 1 error, and pcript $>0.05$ )

$Z_{\beta}=$ standard normal variate for power or type 2 error $=0.84$

$\mathrm{m}=$ number of control subjects per experimental subject $=1: 1$

$P_{1}=$ probability of event in experimental subjects $=18.2 \%\left(\right.$ based on previous study $\left.{ }^{8}\right)$

$\mathrm{P}_{0}=$ probability of event in controls $=37 \% 8$

$p=\left(P_{1}+m P_{o}\right) /(m+1)$

Using a previously reported prevalence of placental parasitemia of $18.2 \%$ by Ibanga Gl et al ${ }^{8}$,

$$
n=\frac{0.96 \sqrt{(1+/ 1) 0.28(1-0.28)}+0.84 \sqrt{0.37(1-0.37) / 1+0.18(1-0.82)}}{=86}
$$

To allow for attrition rate of $10 \%$, the minimum sample size for this study was 95 on each arm.

The participants were counselled on the study and its objectives. Informed Consent was obtained and participants were recruited by consecutive sampling technique. Blood films for malaria parasite were performed for each participant. Based on the results, cases of parasitemia positive and controls of parasitemia negative women were raised. Their case notes were appropriately marked and they were followed up in the clinic till they presented in labour.

A designed proforma was used to collect information including maternal age, parity, gestational age, IPT usage, and use of LLITNs. The social class of the parturients was determined using the classification system proposed by Olusanya, Okpere, and Ezimokhai ${ }^{54}$. Birth weight was measured within one hour of delivery using an electronic weighing scale accurate to \pm 10 gramme. Newborn was classified as normal birth weight ( $\geq 2.5 \mathrm{~kg}$ ) or LBW ( $\leq 2.5 \mathrm{~kg}$ ) according to WHO guidelines ${ }^{55}$. APGAR score of $\geq 7$ in the 
asphyxia. Perinatal asphyxia was classified as mild, if the APGAR score was 6 , moderate if the score was between $4-5$, whereas a score of $0-3$ signified severe perinatal asphyxia ${ }^{56}$.

Pre-delivery, about $3 \mathrm{ml}$ of blood was collected from the peripheral vein of each participant, after aseptic procedure, into a pre-labelled sample bottle containing ethylene diamine tetra-acetic acid (EDTA) for estimation of packed cell volume (PCV) and for determination of intrapartum peripheral parasitemia. The PCV was done using micro-haematocrit method. Two non-heparinised capillary tubes for each subject, each with three- quarter of the tubes filled with blood taken from the $3 \mathrm{ml}$ of peripheral blood already obtained by venepuncture, were sealed at the distal end with plasticine. The capillary tubes containing blood samples were placed in a Hawksley microhematocrit centrifuge and spun at 3000 revolutions per minute for 5 minutes. The PCV was determined using a Hawksley hematocrit reader. The mean of the two values of the PCV was recorded and used. Subjects with PCV below $30 \%$ were regarded as being anaemic. This was based on the finding by Lawson that, in African women, no adverse effect occurred in them or their babies at a hematocrit level of $30 \%$ and above, hence his advocating for that value ${ }^{57}$. The WHO however defines anaemia in pregnancy as hematocrit of less than $33 \% 58$.

After delivery of the baby, $3 \mathrm{ml}$ of blood was collected from the placenta end of the cord into an EDTA sample bottle for determination of malaria parasite (congenital malaria). After delivery of the placenta, a section of it measuring about $2 \mathrm{~cm} \times 2 \mathrm{~cm} \times 1 \mathrm{~cm}$ was biopsied from the maternal surface using a scalpel. The specimen was put in a plane bottle, fixed in $10 \mathrm{ml}$ neutral buffered formalin, and sent to the histology laboratory for processing. The blood specimens were properly labelled and sent to the laboratory for analysis.

Thick and thin blood films preparation and staining were achieved with a drop of cord or peripheral blood placed on the middle portion of a clean $76 \mathrm{~mm} \times 25 \mathrm{~mm}$ microscope slide. A thick film was made by dispersing the drop to fill a large circle at the middle of the slide. A thin film was prepared to be thinner than thick film, in such a way that newsprint could be read through it. The smears were allowed to air-dry. The thin blood smears were fixed in absolute ethanol for 5 seconds before being placed on the rack for 2 minutes. The slides were stained in a trough containing $3 \%$ Giemsa stain for 30 seconds and thereafter rinsed in a buffer solution to maintain a $\mathrm{PH}$ of 7.2. The slides were allowed to air-dry before microscopic examination. The stained smears were examined under $\times 100$ oil immersion lens of a binocular light microscope. The diagnosis of malaria was based on identification of asexual stages of Plasmodium species on the thick blood film, while thin film was used for species identification. Parasite density was determined by counting the number of parasites per High Power Field (HPF) and ranged from $+(1-10$ parasites per $100 \mathrm{HPF}),++(>10$ parasites per $100 \mathrm{HPF}),+++(1-10$ parasites in one HPF), and ++++ (>10 parasites in one HPF). The slides were reported as negative if no parasite was identified per 100 power fields ${ }^{3}$.

The placental biopsies were processed using standard techniques. Sections about $5 \mu \mathrm{m}$ thick were made and stained with haematoxylin and eosin $(\mathrm{H} \infty \mathrm{E})$ and then examined using light microscopy by the lalaria pigments, placental morphology, and 
signs of infections other than malaria. Placental malaria was defined as the presence of parasites and/or pigments in the monocytes in the intervillous space of the placenta as described by Bulmer et $\mathrm{al}^{22}$.

Primary outcome measure was prevalence of placental malaria and the association between placental malaria and maternal anaemia, while the secondary outcomes were:

1. Association between placental malaria and dose of IPT

2. Relation between placental malaria and fetal outcomes like birth weight, NICU admission, stillbirth, and congenital malaria.

3. Relation between parity and placental malaria

\section{STATISTICAL ANALYSIS}

Data was collected, tabulated, and then statistically analysed using Statistical Product and Service Solutions (SPSS) software (version 20, Chicago IL, USA). Numerical variables were presented as mean and standard deviation (Mean $\pm S D$ ), while categorical variables were presented as numbers and percentages. Statistical comparisons and test of significance between positive and negative groups were calculated using Chi-square test $\left(\mathrm{X}^{2}\right)$ for categorical variables. The strength of association between variables was quantified using Odds ratio $(\mathrm{OR})$ and Confidence $(\mathrm{Cl})$. Logistic regression was used to analyze factors associated with the main outcome variables. A p-value cript $>0.05$ was considered statistically significant.

\section{Results}

One hundred and ninety (190) participants were recruited into the study, comprising 95 in the peripheral malarial parasitemia positive group (Group 1) and 95 in the peripheral malaria parasitemia negative group (Group 2). Of the 190 participants in the study, 78 had evidence of placental parasitisation, thus giving the prevalence of placental malaria as $41.05 \%$. Out of the 78 participants that had placental parasitisation, 36 were in group 1 while 42 were in group 2 . Thus, the prevalence of placental parasitisation for cases and controls were respectively $37.89 \%$ and $44.21 \%$. Also, 56 participants had positive cord blood malaria parasite, thus giving the prevalence of congenital malaria as $29.47 \%$. The mean gestational age at delivery was $38.46 \pm 1.1$ weeks while the mean birth weight was $3.16 \pm 0.50 \mathrm{~kg}$. The mean maternal packed cell volume at delivery was $31.05 \pm 2.5 \%$. There were 34 low birth weight infants in the study, giving the prevalence of low birth weight to be $17.89 \%$. Out of the 34 low birth weight infants, $32(94.12 \%)$ of them were delivered by mothers that had positive placental parasitemia.

Table 1 above shows that majority of the participants were married $91(95.8 \%)$ and $90(94.7 \%)$ for group 1 and group 2 respectively. There was no statistically significant difference in the socio-demographic characteristics of the participants except for social class where majority were in class 1 and 3 for group 1 and in class 3 and 4 for group 2 respectively. The mean maternal age at delivery for group 1 and group 2 
Table 2 above shows the association between placental parasitemia and maternal antenatal characteristics for both arms of the study. There was no significant association between placental parasitemia and any of the antenatal factors. Majority of the participants who had placental parasitisation were primigravidae in both groups, representing $50.0 \%$ and $42.9 \%$ respectively. Fewer women in group1 (36) than in group 2 (42) had evidence of placental parasitisation. All the six women that were below 20 years of age in the study had placental malaria. The use of insecticide treated net and the number of doses of IPT taken did not significantly affect placental parasitisation.

Table 3 above shows that placental parasitemia was not significantly associated with any of the fetomaternal outcomes in both arms of the study. A significant proportion of mothers that were anaemic, 46(59.0\%) had evidence of placental parasitisation.

There was no significant association between placental parasitemia and peripheral parasitemia. Majority of women with placental parasitemia had no peripheral parasitemia.

Tables 5 and 6 above show the logistic regression models for factors associated with maternal anemia and low birth weight respectively. Table 5 shows that placenta parasitemia, parity, and social class were significantly associated with maternal anemia. In table 6, only placental parasitemia and maternal anemia were significantly associated with low birth weight.

\section{Discussion}

A total of 36 cases and 42 controls had positive placental parasitemia. This probably buttresses the fact that absence of peripheral parasitemia does not rule out placental parasitemia as shown in many other studies $^{3,16,34}$. The prevalence of placental parasitemia in this study was $41.05 \%$. This value is higher than $18.2 \%$ and $19.0 \%$ previously reported in $U_{y o}{ }^{8}$ and Abeokuta ${ }^{28}$ respectively. The high prevalence of placental parasitemia in this study probably shows the superiority of placental histology over placental blood film used in the two studies above for the diagnosis of placental parasitemia. Fehintola $\mathrm{et}^{\mathrm{al}^{21}}$ in lle-Ife and $\mathrm{Omer}^{2}$ et al in Sudan respectively reported higher prevalence of $48 \%$ and $58.9 \%$. They attributed the high prevalence to poor compliance with intermittent preventive therapy with SuphadoxinePyrimethamine. In addition to the variation in the diagnostic tools used in the detection of the malaria parasite, other factors that could account for these variations in prevalence were variations in community-acquired immunity, case selection, resistance to malaria chemoprophylaxis and booking status of participants ${ }^{3,21}$.

There was no significant association between low parity and placental parasitemia from this study. This finding is not consistent with findings from most other studies probably because of the methodology used in this study in which placenta parasitemia positive cases and placenta parasitemia positive controls were matched. This findings may have also resulted from the fact that, with use of IPT, LLITNs, and prompt case treatment of malaria, most of the peripheral parasitemia positive patients (cases) were

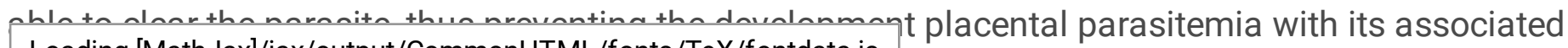
Loading [MathJax]/jax/output/CommonHTML/fonts/TeX/fontdata.js 
adverse effects. Although the majority (46.2\%) of the placental parasitemia positive cases and controls in this study were primigravida, this was still not significant probably because of the above-adduced reasons. Bassey et $\mathrm{al}^{3}$ in their cross-sectional study in Port Harcourt, demonstrated a 5.6-times increase in the risk of developing placental malaria in primigravidae compared to multiparous women which was significant. Rabi et al $^{1}$ in Tanzania also showed similar finding. These findings may be explained by the fact that primigravidae are susceptible to placental malaria because they express specific placental receptors that facilitate binding of parasitized erythrocytes to the placental tissue. This is less likely in multigravid women because, with subsequent deliveries, they acquire blocking antibodies that prevent such binding from occurring $3,8,21$.

The odds of developing maternal anemia among cases was 1.462 times the odds of developing it among the controls. This represents a weak association between placental parasitemia and maternal anaemia, and is not statistically significant $(\mathrm{OR}=1.462,95 \% \mathrm{Cl}: 0.587$ to $3.638, p=0.560)$. This is not consistent with findings from other studies probably because of this study design where placental parasitemia positive cases where matched with placental parasitemia positive controls. When factors that contribute to maternal anemia were subjected to multivariate logistic regression model, placental parasitemia was the most highly significant factor $(\mathrm{OR}=3,95 \% \mathrm{Cl}: 1.425$ to $6.318, \mathrm{p}=0.004)$. Fehintola et $\mathrm{al}^{21}$ and by Bassey et $\mathrm{al}^{3}$ documented a significant association and showed a 2.6-fold increased risk of maternal anemia. The mean maternal hematocrit of the respondents at delivery was $31.05 \pm 2.5 \%$. The decrease in hematocrit is believed to result from the fact that both parasitized and unparasitized erythrocytes are destroyed by the spleen during malaria infestation ${ }^{8,21}$. The accumulation of pigmented monocytes in the placenta has been proposed to be associated with maternal anemia probably due to the release of proinflammatory mediators which could lead to suppression of erythropoiesis. In pregnancy, this may be confounded by iron deficiency, hookworm infestation, and poor nutrition ${ }^{21}$. In this study, meticulous efforts were made to exclude other causes of anemia in pregnancy such as multiple pregnancy, sickle cell anemia, and women with retroviral disease.

All the participants in this study received at least a dose of IPT. It was noted that placental parasitemia was not significantly associated with dose of IPT taken. Similar finding was noted by Mosha et al ${ }^{16}$ in Tanzania and Joanne et al ${ }^{32}$ in Ghana where they did not note any dose-dependent relationship between IPT compliance and placental malaria in their studies. Although the findings from this study may have resulted from the study design used, the possible reasons they adduced for their own findings include insufficiently powered study to determine the effect of increasing IPT dose on placental malaria, lack supervision of SP intake, or inaccurate SP dose reporting. Another possible explanation for the finding noted in this study is that some of the cases (group 1) may have developed overt malaria symptoms during antenatal period, thus leading to case treatment with antimalaria agents. Fehintola et $\mathrm{al}^{21}$ in Ile-lfe and Bassey $\mathrm{G}$ et $\mathrm{al}^{3}$ in Port Harcourt showed a significant association between poor compliance to IPT and placental parasitemia. 
The prevalence of low birth weight in this study was $17.89 \%$. This was similar to $16.4 \%$ documented by Nwali et $\mathrm{al}^{7}$ but was lower than the $31.8 \%$ noted by Fehintola et $\mathrm{al}^{21}$ in lle-lfe. The reason for this discrepancy may be because of proper utilization of IPT in this study since all the participants were booked and received Sulphadoxine-Pyrimethamine unlike the lle-Ife study that involved both booked and unbooked participants. Additionally, risk factors for low birth weight such as hypertensive disorders of pregnancy, multiple gestation, and sickle cell disease were excluded from this study. In this study, the odds of low birth weight among the cases are 1.3 times the odds of developing it among the controls. This represents an association, although a weak one, between placental parasitemia and low birth weight. There was therefore no significant difference between the two groups in terms of low birth weight $(\mathrm{OR}=1.3,95 \% \mathrm{Cl}: 0.526$ to $3.215, \mathrm{p}=0.737)$. This finding was not in concord with many other studies $^{2,7,21,43}$ and is probably due to the study design used here. This finding may also be because most of the peripheral parasitemia positive cases were able to clear the parasites, thus preventing placenta parasitisation which could lead to adverse fetomaternal effects. When factors contributing to low birth weight were subjected to multivariate logistic regression model, only placental parasitemia $(O R=15.775$, $\mathrm{Cl}=3.034-82.019, \mathrm{p}=0.004$ ) and maternal anemia ( $\mathrm{OR}=0.127,95 \% \mathrm{Cl}=0.031-0.515, \mathrm{P}=0.004)$ showed strong association with low birth weight. Similar finding was noted by Ibanga et al ${ }^{8}$. It has been postulated that placental malaria leads to accumulation of monocytes in the placenta bed, causing release of cytokines that lead to hypoxia and reduction in the transplacental transfer of nutrients. This leads to intrauterine growth restrictions(IUGR) and subsequent low birth weight ${ }^{7,21}$.

The two groups were similar in terms of intrapartum peripheral parasitemia $(p=0.231)$. This may imply that some of the controls developed new peripheral parasitemia while some of the cases were unable to clear the peripheral parasitemia. This is similar to the finding by Bassey et $\mathrm{al}^{3}$ who demonstrated that despite the absence of malaria parasite in peripheral and cord blood, placenta parasitemia still occurs in some patients. Ibang et $\mathrm{al}^{8}$ noted that placental parasitemia is positively correlated with peripheral parasitemia. They opined that some women might have cleared the peripheral parasitemia at the time of delivery mostly due to use of IPT and case management of malaria in pregnancy and such women will have negative malaria parasite even in the presence of placental parasitemia.

The prevalence of congenital malaria in this study was $29.47 \%$ and was lower than the $50.5 \%$ documented by Bassey et $\mathrm{al}^{3}$ in Port Harcourt. The low prevalence noted in this study may be because of proper use of IPT and case management since all the participants were booked and received Suphadoxine-Pyrimethamine. The odds of developing congenital malaria among the cases was 1.49 times the odds the odds of developing it among the controls. This represents association (although weak) between congenital malaria and peripheral parasitemia. Congenital malaria in this study was not significantly different in the two groups (OR $=1.49,95 \% \mathrm{Cl}: 0.609$ to $3.648, \mathrm{p}=0.520)$. This may be because most of the peripheral malaria positive cases were able to clear the parasite prior to delivery without placental parasitisation. It could also be due to the fact that although the controls had no peripheral parasitemia at recruitment, they still had placental parasitemia because of the poor correlation a. Most studies $2,3,21$ documented a significant 
association between placental parasitemia and congenital malaria. None of the babies with positive cord blood MP (congenital malaria) had clinical manifestation of malaria at birth. This may be due to the effect maternal antibodies ( $\mathrm{gG}$ ) transferred to the fetus. These maternally acquired antibodies have been postulated to delay or modify the onset of clinical manifestation of congenital malaria ${ }^{3}$.

In this study, there was no significant difference between the two groups in terms of low Apgar scores at 5 minutes and admission into newborn intensive care unit. The babies admitted into NICU were macrosomic $(>4 \mathrm{~kg})$ and were at risk of neonatal hypoglycaemia. There was no stillbirth or maternal mortality in this study. Similar findings were noted by Joanne et al ${ }^{32}$ in Ghana. This finding may have occurred because the participants were well-selected, low-risk, and booked women that received at least a dose of IPT.

The major limitation was that being an institutionally-based study, its findings might not reflect the true situation among the population. In addition, cord blood and placenta samples were taken at delivery. Thus the presence or absence of malaria parasites might not reflect past or chronic infection which may have had adverse effect on the pregnancy and perinatal outcome. However, with a large sample size of 190 and the use of multivariate logistic regression model to evaluate factors associated with the main outcome variables, these limitations were considerably mitigated and the study adequately powered.

\section{Conclusion}

Placental parasitemia is a major complication of malaria in pregnancy and is associated with adverse feto-maternal effects. There is a high prevalence of placental parasitemia in the study population. The two study groups are similar in all the compared fetomaternal outcomes and maternal antenatal characteristics. This may be because most women with peripheral parasitemia were able to clear the parasites prior to delivery probably due to use of IPT and prompt case management for those that developed overt malaria symptoms. It also buttresses the fact that absence of peripheral parasitemia as in the cohorts does not exclude placental parasitemia.

\section{Recommendations}

Pregnant women should be encouraged to book early and uptake optimum doses of IPT for malaria. They should also be encouraged to present early for prompt and effective case treatment. Government should also intensify efforts aimed at reducing malaria in pregnancy with its associated fetal and maternal complications.

\section{Declarations}

\section{Ethics approval and consent to participate}

Ethical approval was sought and obtained from the Health Research and Ethics committee of Alex Loading [MathJax]/jax/output/CommonHTML/fonts/TeX/fontdata.js . The participants signed the informed consent 
form before they were enrolled into the study.

\section{Consent for publication}

The informed consent form signed by the participants also contained consent for publication

\section{Availability of Data and materials}

The data used in this study are available in the patient's records at Alex Ekwueme Federal University Teaching Hospital, Abakaliki, Ebonyi state, Nigeria. The collected data were also kept in the personal computer of the lead researcher

\section{Competing interest}

The authors declare no conflict of interest.

\section{Funding}

The authors provided funds for the research

\section{Authors' contribution}

Wilson Ndukwe Nwigboji: Conception of the study, design of the work, acquisition, analysis and interpretation of the data

John Okafor Egede: Conception of the study, design of the work, acquisition, analysis, interpretation of the data and revision of manuscript

Peace Chinyere Igwe: Collection of data, analysis and interpretation of data

Matthew Igwe Nwali: Conception of the study, design of the work, acquisition, analysis and interpretation of the data

Gregory Chinedu Nwigwe: Design of the work, draft and revision of the manuscript

Alfred Adiele: Conception of the study, design of the work, acquisition, analysis and interpretation of the data

Felix Edegbe: Collection of data, analysis and interpretation of data

Ikechukwu BO Dimejesi: Design of the work, draft and revision of the manuscript

Lawrence 0. Omo-Aghoja: Conception, design, draft and revision of the manuscript

\section{Acknowledgement}


The authors wish to acknowledge the contributions of residents, house officers and nurses/midwives in the department of Obstetrics and Gynaecology who helped in the collection data for this project.

Authors' information

Not applicable

\section{References}

1. Rabi N, Adinan J, Dominic M, Chilongola J. Risk factors for placental malaria and associated adverse pregnancy outcome in Rufiji, Tanzania: a hospital based cross sectional study. Afr Health Sci. 2015;15(3):810-8.

2. Omer SA, Idress HE, Adam I, Abdelrahim M, Noureldein AN, Abdelrazig AM, et al. Placental malaria and its effect on pregnancy outcomes in Sudanese women from Blue Nile State. Malar J Sept. 2017;16(1):374-81.

3. Bassey G, Nyengidiki TK, John CT. Prevalence of plasmodium parasitemia and pregnancy outcome in asymptomatic patients at delivery in a University Teaching Hospital in Nigeria. Niger $\mathrm{J}$ Clin Pract. 2015;18:27-32.

4. Apare-Addo HO, Odoi AT. Malaria in pregnancy. In: Kwawukume EY, Ekele BA, Danso KA, Emuveyan $\mathrm{EE}($ eds), Comprehensive obstetrics in the tropics second edition;2015, pp 321-331.

5. Malaria in pregnancy. Diagnosis and treatment. Centre for Disease Control (CDC), 2017. (Accessed in Nov 2017).

6. Ezebialu IU, Ezebialu CU. Prevalence, pattern, and determinants of placental malaria in a population of south eastern Nigerian parturients. Int J of Infect Dis. 2012;16(12):860-5.

7. Nwali MI, Umeora OUJ, Ozumba BC, Onoh RC, Agwu UU, Agboeze J. Outcomes of asymptomatic malaria parasitemia in neonates in a tertiary hospital, southeast Nigeria. Niger Med J. 2014;55(1):250-3.

8. Ibanga GI, Abasiattai AM, Bassey EA, Ukpa M, Olatunbosum OA, Ekrikpo U. Placental malarial parasitemia and pregnancy outcome among parturients in a tertiary hospital in south-south Nigeria. Asian J Med sci. 2015;16(6):53-9.

9. National guidelines and strategies for malaria prevention and control during pregnancy, second edition; 2014. Federal Ministry of Health, Nigeria.

10. Fana SA, Bunza MDA, Anka SA, Imam SU, Nataala SU. Prevalence and risk factors associated with malaria infection among pregnant women in a semi- urban community of North- western Nigeria. Infect Dis poverty. 2015;4(1):24-32.

11. Alphonse O, Alfred B, Amidou D, Edith C, Christiane B, Issa N, et al. Transplacental transmission of Plasmodium falciparum in a highly malaria endermic area of Burkina- Faso. J Trop Med. 2012;2012:1-7. 
12. Sharma L, Shukla G. Placenta malaria: A new insight into the pathophysiology. Front Med. 2017:4:117-25.

13. Sarr D, Cooper CA, Bracken TC, Martinez-Uribe O, Nagy T, Moore JM. Oxidative stress: A potential therapeutic target in placental malaria. Immuno Horizons. 2017;1(4):29-41.

14. Ahmed R, Singh N, Feiko OK, Bharti PK, Singh PP, Udhayakumar V, et al. Placental infections with histologically confirmed Plasmodium falciparum are associated with adverse birth outcomes in India: a cross- sectional study. Malar J. 2014;13:232-41.

15. Nwonwu EU, Ibekwe PC, Ugwu Jl, Obarezi HC, Nwagbara OC. Prevalence of malaria parasitemia and malaria related anaemia among pregnant women in Abakaliki, southeast Nigeria. Niger J Clin Pract. 2009;12(2):182-6.

16. Mosha D, Chilongola J, Ndeserua R, Mwingira F, Genton B. Effectiveness of Intermittent Preventive Treatment wiyh sulfadoxine-pyrimethamine during pregnancy on placental malaria, maternal anaemia, and birth weight in areas with high and low malaria transmission intensity in Tanzania. Trop Med Int Health. 2014;19(9):1048-56.

17. Autino B, Corbett $Y$, Castelli D. Pathogenesis of malaria in tissues and blood. Meditter $J$ Haematol Infect Dis. 2012;4(1):1-8.

18. Milner DA. Rethinking cerebral malaria pathology. Curr Opin Infect Dis. 2010;23:456-63.

19. Chakravorty SJ, Craig A. The role of ICAM- 1 in Plasmodium falciparum cytoadherence. Eur J Cell Biol. 2005;84:15-27.

20. Fried M, Duffy PE. Designing a VAR2CSA- based vaccine to prevent placental malaria. Science Direct. 2015;33(52):7483-8.

21. Fehintola AO, Fehintola FO, Loto OM, Fasuba OB, Bakare B, Ogundele O. Pregnancy and fetal outcome of placental malaria parasitemia in Ile- Ife, Nigeria. Trop J Obst Gynaecol. 2016;33:310-6.

22. Mate S, Dzigbodi K, Azanu W, Ampofo AE, Doe FP, Asamoah I, et al. Adverse obstetric outcomes among women with placental malaria from peri- urban Ghana. Int J Research Med Health Sciences. 2016;6(1):5-11.

23. Conroy Al, Silver KL, Zong, et al. Compliment activation and the resulting placental insufficiency drives fetal growth restriction associated with placenta malaria. Cell Host Microbes. 2013;13(2):21526.

24. Kidima WB. Syncytiotrophoblast function and fetal growth restriction during placental malaria: update and implication for future. Biomed Res Int 2015; 1-9.

25. Rogerson SJ, Hviid L, Duffy PE, Leke RF, Taylor DW. Malaria in pregnancy: Pathogenesis and immunity. Lancet Infect Dis. 2007;7:105-17.

26. Ayres PM, Mandel CT, Pehrson C, Mao Y, Resende M, Daugaad M. Placental sequestration of Plasmodium falciparum malaria parasites is mediated by interaction between VARS2CSA and chondroitin sulphate A on syndecan-1. PLoS Pathog. 2016;12(8):e1005831. 
27. Sander AF, Salanti A, Lavstses T, Nielsen MA, Theander TG, Lehe RG, et al. Positive selection of Plasmodium falciparum parasites with multiple VAR2CSA- type PfEMP1 genes during the course of infection in pregnant women. $J$ Infect Dis. 2011;203:1679-85.

28. Babalola AS, Oluwafunmilayo Al, Sammy OS, Eniola F.. Babalola, et al. Risk factors associated with occurrence of placental malaria in a population of parturients in Abeokuta, Ogun state. MWJ. 2015;6(8):1-6.

29. Ayoola OO, Whatmore A, Balogun WO, Jarrett OO, Cruickshank JK, Clayton PE. Maternal malaria status and metabolic profiles in pregnancy and in cord blood: relationships with birth size in Nigerian infants. Malar J. 2012;11(75):4-9.

30. Ndam NT, Denoeud-Ndam L, Doritchamou J, Viwami F, Salanti A, Morten AN, et al. Protective antibodies against placental malaria and poor outcome during pregnancy in Benin. Emerg Infect Dis. 2015;21(5):813-23.

31. Mayor A, Rovira-vallbona E, Machevo S, Bassat Q, Aguillar R, Quinto L, et al. Parity and placental infection affect antibody response against Plasmodium falciparum during pregnancy. Infect Immun. 2011;79:1654-9.

32. Joanne HM, Tom AJS, Stephen A. Placental malaria and the relationship to pregnancy outcome at Gushegu district hospital, northern Ghana. Trop Doct April. 2012;42:80-4.

33. Maestre A, Carmona- Fonseca J. Immune responses during gestational malaria: a review of the current knowledge and future trend of research. J Infect Dev Ctries. 2014;8:391-402.

34. Plotkin M, Said K, McElroy PD. Placental malaria is rare among Zanzibari pregnant women who did not receive intermittent preventive treatment in pregnancy. Am J Trop Med Hyg. 2014;91(2):367-73.

35. Mbah JO, Njoku OO, Nnachi AU, Nwinyimagu AJ. Incidence of antenatal malaria parasitemia and the effect on the haemoglobin profile of pregnant women in Enugu east local government area, Enugu Nigeria. Am J Epide Infect Dis. 2015;3(5):88-94.

36. Isah AY, Amanabo MA, Ekele BA. Prevalence of malaria parasitemia among asymptomatic pregnant women attending a Nigerian teaching hospital. Ann Afr Med. 2011;10(2):171-4.

37. Rogerson SJ, Ordi J. Pathology and pathophysiology of placental malaria. In: Hommel M, Kremsner P, editors. Encyclopedia of malaria 2015, Springer New York.

38. Uneke CJ. Impact of placental plasmodium falciparum malaria on pregnancy and perinatal outcome in sub- Saharan Africa. Yale J Biol Med. 2007;80(2):39-50.

39. Kasiulevicus V, Sapoka V, Filipaviciute R. Sample size calculation in epidemiological studies. Gerontologija. 2006;7(4):225-31.

40. Okpere EE.. Okpere ED. Maternal mortality in Ngeria in Clinical Obstetrics revised edition. EE. UNIBEN PRESS, University of Benin, Benin city, Nigeria;; 2004. p. 394.

41. Wardlaw TM. Low birth weight: country, regional, and global estimates. UNICEF; 2004.

42. Aliyu I, Lawal TO, Onankpa B. Hypoxic-ischaemic encephalopathy and the Apgar scoring system: The experience in a resource-limited setting. J Clin Sci. 2018;15:18-21.

Loading [MathJax]/jax/output/CommonHTML/fonts/TeX/fontdata.js

Page 15/16 
43. Esike CO, Anozie CB, Onoh RC, Sunday UC, Nwokpor OS, Umeora OUJ. The prevalence of anaemia in pregnancy at booking in Abakaliki, Nigeria. Trop J Obstet Gynaecol. 2016;33(3):332-6.

44. Omoigbodum AO. Recent trends in the management of anaemia in pregnancy. Trop J Obstet Gynaecol. 2004;21:1-3.

\section{Tables}

Due to technical limitations, table 1 to 6 is only available as a download in the Supplemental Files section.

\section{Supplementary Files}

This is a list of supplementary files associated with this preprint. Click to download.

- Tables.docx 